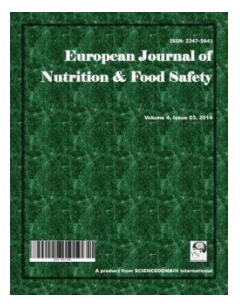

European Journal of Nutrition \& Food Safety

5(5): 1159-1160, 2015, Article no.EJNFS.2015.487

ISSN: 2347-5641

SCIENCEDOMAIN international

www.sciencedomain.org

\title{
Assessment of Implementation of an Anaemia Reduction Initiative Including Blanket Supplementary Feeding Distributing LNS and MNP on Anaemia in a Protracted Refugee Situation
}

\author{
Carlos Grijalva-Eternod ${ }^{1,2^{*}}$, Chafik Meziani $^{3}$, Melody Tondeur ${ }^{3}$, \\ Caroline Wilkinson ${ }^{2}$, Carmel Dolan ${ }^{2}$ and Andrew Seal ${ }^{1,2}$ \\ ${ }^{1}$ UCL Institute for Global Health, London, UK. \\ ${ }^{2}$ Emergency Nutrition Network, Oxford, UK. \\ ${ }^{3}$ United Nations High Commissioner for Refugees, Geneva, Switzerland.
}

Article Information

DOI: 10.9734/EJNFS/2015/21299

Special Editors:

Lucie Bohac, Micronutrient Forum Secretariat, Canada. Klaus Kraemer, Director, Sight and Life, Basel, Switzerland.

Chief Editor

Prof. Hans Verhagen, Senior Scientific Advisor 'Nutrition and Food Safety', National Institute for Public Health and the Environment (RIVM), P.O.Box 1, 3720 BA, Bilthoven, The Netherlands.

\author{
Conference Abstract
}

Received $5^{\text {th }}$ February 2015

Accepted $1^{\text {st }}$ March 2015

Published $14^{\text {th }}$ August 2015

\begin{abstract}
Objectives: Micronutrient malnutrition, commonly manifested as stunting and anaemia, is a persistent public health problems in populations experiencing a protracted refugee situation like the Western Sahara refugees living in south-west Algeria. A UNHCR and partners' strategy to address this issue was to implement a blanket supplementary feeding programme providing lipid-based nutrient supplements (LNS) and micronutrient powders (MNP) to children aged 6-35 and 36-59 months, respectively. We present data on anaemia prevalence in children aged 6-59 months after two-years of implementation.

Methods: Routine pre- (2010) and post-intervention (2012) cross-sectional nutrition surveys were conducted assessing anaemia $(\mathrm{Hb}<11 \mathrm{~g} / \mathrm{dL})$ in four Western Sahara refugee camps. Data on coverage was obtained by questionnaire in the post-intervention nutrition survey.

Results: Overall, we observed a significant reduction in anaemia prevalence in children 6-59 months between baseline (52.8\%; 95\% Cl: 49.1-56.6) and end-line (28.4\%; 95\% Cl: 25.7-31.0); and an increase in mean haemoglobin concentration from $10.7 \mathrm{~g} / \mathrm{dL}$ (s.d.:1.7) to $11.6 \mathrm{~g} / \mathrm{dL}$ (s.d.:1.4). A similar pattern of differences for anaemia prevalence was observed when the analysis was stratified by camp. Coverage for LNS among children aged 6-35 months was $70 \%$, contrasting with $14 \%$ for MNP among children aged 36-59 months.
\end{abstract}

Correspondence: Lucie Bohac, Coordinator, Micronutrient Forum Secretariat (email: Ibohac@micronutrient.org) Note: This abstract was presented at "The Micronutrient Forum Global Conference - Bridging Discovery and Delivery", 2-6 June 2014, Addis Ababa, Ethiopia. 
Conclusions: A blanket supplementary feeding programme providing LNS and MNP is associated with anaemia reduction among children living in a protracted refugee situation. The discrepancy in reported coverage for each product suggests that this reduction could be largely attributed to differences in adherence. Further research is needed to understand potential negative interactions in adherence during concomitant distributions of LNS and MNP.

(c) 2015 Grijalva-Eternod et al.; This is an Open Access article distributed under the terms of the Creative Commons Attribution License (http://creativecommons.org/licenses/by/4.0), which permits unrestricted use, distribution, and reproduction in any medium, provided the original work is properly cited. 